\title{
Introduction to professional sports teaching central Africa the cultivation of the students' interest in sports
}

\author{
Fanwei Meng \\ Changchun University of science and technology, Changchun 130000, China \\ 13742883@qq.com
}

Keywords: non-professional sports, Sports teaching, Interest in sports, To cultivate

\begin{abstract}
: this article from the sports teaching china-africa professional sports the cultivation of the students' interest in sports, this paper discusses the main factors affecting the forming, puts forward the corresponding training methods according to these factors and the method, thus improve the non-professional sports physical health level of students, promote the healthy development of the body.
\end{abstract}

Refers to a kind of with interest in the understanding of the emotional color, it is mainly based on some things to know and explore, on the basis of the need to seek truth is a kind of psychological tendency.Einstein once said: "interest is the best teacher.Once a person has the interest, as the power, he will be in a very full enthusiasm into the do, also, in the sports teaching, if want to let the students love sports, like this course, should stimulate their enthusiasm for physical education, cultivate their interest in sports, and physical education more rich and colorful ".

\section{1. the concept of interest in sports}

Sports interest is a positive recognition, priority is engaged in the activity of a kind of psychological tendency, and is linked to participate in sports activities need to be intentional activities. if a man love sports in the sports activities he will be in a positive attitude, energy involved, so the sports interest is one of the important motivation of people to participate in sports activities, and affects the activities involved in the specific direction and basic strength.

2. the current situation of the non-professional sports students' interest in sports as well as the influence factors

\section{1 the current situation of the non-professional sports students' interest in sports}

A large number of literature and the research results show that the students' interest in sports as the growth of the age, the development form of constant change of the body, especially the non-professional sports students, age, the higher the grade of students, their interest in sports in good education teaching environment is more stable, and has definite selectivity, some students love sports, and some are interested in sports do not, is also evident on gender differences, boys interest from the fierce competition and confrontational sports, girls are obvious in activity of inert accident, afraid of dirty, tired, afraid pain bitter, afraid of the sun and of sweating, fear, fear of injury, students of physical education, a negative attitude. At the same time, in the right education and under the influence of personal interests and hobbies, part of the non-professional sports students also have interest on some sports activities.

\section{2 the influencing factors of non-professional sports students' interest in sports}

\subsection{1 psychological factors}

Lack of correct understanding of physical education, entertainment, leads people to think that sports is a kind of life with this understanding, nature won't be taken seriously in the sports activities, thus losing the rigor and discipline of sports itself.In sports, especially have experience failure and setbacks of the students, most of the students to sum up experience and lessons in failure and 
setbacks, but there are still some students dare not face right after face failure and setbacks, not willing to actively participate in, or even far away from the collective activities.

\subsection{2 physiological factors}

Some students short stature, body fat, such as weak, or the body symptoms of the disease, they always feel inferior to others, dare not to participate in sports activities, can't complete the task in accordance with the requirements of the teacher and the standard, lead to self-confidence, gradually lose interest in sports activities.

\section{PE teaching china-africa sports professional ways for the cultivation of the students' interest in sports and method}

\section{1 sports teaching china-africa professional sports ways for the cultivation of the students'} interest in sports

\subsection{1 respecting individual development differences, enhance the students learning interest in} sports

In sports activities, teachers should begin with understanding students, because the students' personality traits and physical differences, mastery of sports skills and sports knowledge is different, so the teacher should be equal democracy in the sports activities, psychological compatibility, adhere to the principle of teaching students, especially to those poor sports foundation, poorly coordinated student, should give more encouragement and praise.

\subsection{2 the right sports learning method, cultivating strong interest in learning}

Learning is an important factor to improve the movement technology, active learning, to master the correct method of exercise is conducive to learning, easy to learn, in the right way, the performance of the rapid improvement, learning motivation is strong, strong study interest.On the other hand, study hard, often encounter learning difficulties, reduced the enthusiasm of learning.Impact on the students' interest in learning sports.Now advocates autonomy, cooperation, explore learning, stimulate students interest in learning, improve performance, has a positive role in promoting.

\subsection{3 in all kinds of sports, arouse the students' interest in learning sports}

Sports is an effective way to enhance the collective consciousness, competitive consciousness, is one of the effective methods to cultivate interest in sports, is the basis of the practice of promoting sports meet, evolution characteristics, often change in the position in the competition, the students participate in sports activities after successful experience, improve sports activities in confidence, thus can promote the students to go ahead, take an active part in physical exercise, participate in competition, win victory.In physical education, should be in this way, train and motivate the students' competition, and at the same time also can understand most of the students sports performance, sports competition test sports teaching effect, the school should be a variety of reward, to improve the students' physical training, enhance the students' sports consciousness, cultivate the students' interest in sports.

3.1.4 the construction of a harmonious relationship between teachers and students, create a good learning atmosphere

Sports teaching is a bilateral activity, we need to put the students' learning and teachers teaching fuses in together, a harmonious and happy learning environment is also essential, the harmonious relationship between teachers and students can cultivate the students' learning motivation, improving the students' enthusiasm and initiative. So in the process of physical education teaching, the teacher should concern every one of us, respect everyone, no sarcasm students, and students become permanent friends, only in this way can let students feel the teacher care for them, and by the fear of learning "and" learning ", willing to learn, love learning, like to learn. Which is conducive to the cultivation of the students learning interest in sports.

3.2 sports teaching china-africa sports professional students' interest in sports training methods

\subsection{1 teacher express sincere emotions, stimulate students' interest in sports}

Students' interest in sports and physical education teachers is closely related to emotion, with emotion can be mutual infection, physical education teachers in class, the mood will be a direct 
impact on the students' interest in learning, physical education teachers of activities and emotions, often through their own language, action and praise and show, students emotion so affected.If PE teachers in the class, good mental state, for students to be praised, more favorable for the formation of good class atmosphere, also can improve the students' central nervous excitability, stimulate students interest in sports.of course, can also be seen in the sports teaching, if teachers emotional instability, lack of concentration, teaching no center, no key, even bring life emotion to the classroom, the student temper tantrum, makes the students' interest in learning is affected by the serious and become low, no power, no vitality.Therefore, physical education teacher in class application sincere emotions, vivid language to induce students, stimulate students' interest in physical education of knowledge.

\subsection{2 change student's ideological concept, to improve students' correct understanding of sports}

In the sports teaching, pay attention to strengthen education, raise awareness, change ideas, cultivate interest, teachers should abandon the single teaching mode, through a variety of new forms of education teaching, such as: radio, television, film, video, and other modern teaching methods, students learning education of the students understand the necessity and importance of understanding of sports, sports function, purpose and value of sports.

\subsection{3 pays attention to student's psychological factor, cultivate students' interest in learning sports}

All kinds of activities will be the impact of physical education psychology, physical education teachers should pay attention to students' psychological factors, to improve students' learning interest in sports and students once you have the interest in sports, he will put learning as their own needs, will be hard to carry on the sports study and exercise, so teachers need to focus on students' emotion and attention.In sports teaching of middle school students emotion in intense, complex and diverse, stable mood student sports activities is very important, students emotion will affect the sports achievements and give full play to the body all aspects. Emotional stability is conducive to cultivate their interest in sports activities, improve the quality of the activity.In addition, the students' learning attention, study result of action will be more, there are harvested to make corresponding action, timely adjust their own actions, to achieve the purpose of physical education teaching, therefore, to improve the students' attention is an important factor, stimulate students' active learning and improve teaching quality.

\subsection{4 create good teaching environment, enhance the students' interest in sports}

In physical education teaching activities, venues and related equipment is required, because of the space and equipment arrangement affects the classroom atmosphere, so the clever design of the venues and equipment, to create a good teaching environment, give students a good feeling, make strenuous exercise fatigue brought about by the loss.Also, pay attention to the creation of teaching software and hardware environment, in order to meet the students' psychological demands, by learning to different levels, different levels of students have their own set tough, physical education teachers must set up the idea of equality between teachers and students, often should encourage students to progress, to create a good teaching environment, causes the student to love learning, love learning, learning.

In short, if want to let the students are interested in your course, it is necessary to arouse and cultivate students' interests in the course, to cultivate and arouse interest in sport, is a subtle and complex task, is also an art.As a sports teacher, in the sports teaching to find problems, solve the problem, sum up experience, to cultivate the students' interest in sports as a duty, and throughout the teaching work.As long as we have a strong sense of social responsibility and faith, can stimulate students' interest in sports and to create a quality education in the new period.

\section{References}

[1] Yang hua. Experiment of cultivating the ability of teaching of physical education major students in research [D]. Sichuan normal university, 2011. 
[2] fa-zhong li, juck Qin Yun to set up, de-an zhao. Introduction to "analog electronic technology" course teaching reform [J]. China power education, 2009, (11) : 129-130.

[3] shun-ying Lin. Theory of the ordinary university sports education undergraduate teaching quality guarantee [D]. Fujian normal university, 2008.

[4] li shi. Lin Fu winds. Analyses the sports games in the sports teaching the application [J]. Journal of hotan normal school, 2008. (01) : 210-211 